\title{
Light Scattering Characteristics and Size Distribution of Smoke and Nuisance Aerosols
}

\author{
DARRYL W. WEINERT ${ }^{\dagger}$, THOMAS G. CLEARY, GEORGE W. MULHOLLAND \\ AND PAULA F. BEEVER
}

Building and Fire Research Laboratory, National Institute of Standards and Technology (NIST), Gaithersburg, 20899, MD, U.S.A.

${ }^{\dagger}$ Center for Environmental Safety and Risk Engineering (CESARE), Victoria University, PO Box 14428, Melbourne City MC, Victoria, 8001, Australia

${ }^{\ddagger}$ Principal Fire Engineer, New Zealand Fire Service, PO Box 2133, Wellington, New Zealand

\begin{abstract}
This paper presents the differential mass scattering cross section $\left[\mathrm{m}^{2} \cdot \mathrm{g}^{-1} \cdot \mathrm{sr}^{-1}\right]$ of various non-flaming and flaming fire generated smoke aerosols as well as nuisance aerosols created in the Fire Emulator/Detector Evaluator. These measurements have been determined for two linear polarizations and the scattering angle range of $5^{\circ}$ to $135^{\circ}$ at a wavelength of $632.8 \mathrm{~nm}$. Small diameter particles have been separated from large particles using the forward scattering information. Discrimination of soot generated by flaming fuels from both smoke aerosols generated by non-flaming fires and nuisance aerosols is demonstrated by the ratio of forward $\left(45^{\circ}\right)$ to backward scattering $\left(135^{\circ}\right)$, the polarization ratio, and dependence on scattering parameter, $q=4 \pi \lambda^{-1} \sin (\theta / 2)$.
\end{abstract}

KEY WORDS: detection, smoke, nuisance, light scattering, size distribution

\section{INTRODUCTION}

Much of the potential benefit of automatic smoke detection systems is offset by the problem of repeated unwanted alarms. The ability of a system to discriminate the types of airborne particles arising from different fire types, from potential fires and from nuisance aerosols would be of great practical benefit. This study examines light scattering characteristics of smoke and nuisance aerosols for two main goals: (i) to characterize the particles generated and (ii) to investigate the similarities or differences between particles generated. The first point is of benefit to detector response modeling and testing. The latter goal is aimed at examining different discrimination approaches for fire and non-fire generated aerosols using light scattering. Discrimination of light scattering signals generated by the smoke and nuisance aerosols is important information to consider when reducing the incidence of alarms caused by nuisance aerosols.

To obtain detailed information on the light scattering characteristics of smoke aerosols this study has used an approach that measures the angular distribution of scattered light. This measure is expressed as the differential (angular distribution) scattering cross section per mass, $\sigma(\theta)$, which has the units of area per unit mass of scattering aerosol per solid angle of detector view $\left[\mathrm{m}^{2} \cdot \mathrm{g}^{-1} \cdot \mathrm{sr}^{-1}\right]$ and will be referred to as the differential mass 
scattering cross section. The mass specific scattering measurement is a novel aspect of this work, it enables one to estimate the light scattering of smoke based on a measurement of mass concentration. Previous studies have been conducted with smoke aerosols using normalized scattering data [1] or single angle response [2,3]. In this study soot generated by flaming fires is distinguished from both smoke generated by non-flaming fires and nuisance aerosols using various means. In particular we apply two methods, polarization ratio and $\mathrm{q}$ dependent scattering $\left(q=4 \pi \lambda^{-1} \sin (\theta / 2)\right.$ ), that are inspired by fundamental differences between light scattering from soot agglomerates and other non-agglomerate aerosols.

The general form of agglomerate light scattering [4] can be expressed in terms of a power law relation that reduces to,

$\sigma_{V V}(\theta) \propto q^{-D}$ for $q>R^{-1}$,

where $R$ is the agglomerate characteristic radius (e.g. radius of gyration), and $D$ is the fractal dimension characterizing the spatial mass distribution of the agglomerate. Various studies for in-flame and post-flame soot have reported fractal dimensions to be about 1.7 to 1.85 using laser scattering techniques [5,6]. Universality in morphology and subsequent scattering is related to the fact that all soot shares the same fundamental mechanisms of agglomerate growth [7].

There has been relatively little study regarding the q-dependence of scattering by spheres until recent work by Sorensen and Fischbach [8]. This is surprising given the extensive application of Mie theory to the study of light scattering by spheres.

Size distribution measurements were also conducted, as size is an important quantity on which the light scattering depends. Size information is also of benefit for assessing response of detectors based on other principles such as ionization detectors, or examining smoke aerosol kinetics. The size information presented here in terms of aerodynamic diameter is complementary to that published previously [9-11].

\section{SMOKE AND NUISANCE AEROSOL GENERATION AND SAMPLING}

The majority of smoke and nuisance aerosols examined in this study were generated in the Fire Emulator/Detector Evaluator (FE/DE), a facility designed to emulate the smoke of a fire for fire detector assessment [12,13]. The operating principle of the FE/DE is that of a single pass wind tunnel, into which a smoke or nuisance aerosol is released. A test sensor section contains smoke detectors and instruments to measure various parameters including the light transmission through the generated aerosol, the air velocity (typically $0.2 \mathrm{~m} / \mathrm{s}$ ), temperature, and response of a measuring ionization chamber (MIC). A sampling line was inserted into this section to sample smoke and nuisance aerosol for size distribution measurement and transport to the light scattering apparatus. The sampling was done at a flow rate of about $8.7 \mathrm{~m} / \mathrm{s}$ (light scattering) and $13 \mathrm{~m} / \mathrm{s}$ (size distribution) from $50 \mathrm{~mm}$ below the top of the sensor section's duct, which had a height of $304 \mathrm{~mm}$.

The non-flaming fuels examined in the FE/DE for this study were beech wood blocks, cotton lamp wick, and polyurethane foam. The wood blocks are those specified in EN54 (part 9, test fire 2) [14], similarly the cotton lamp wick is the same fuel as specified in EN54 (part 9, test fire 3) and is also used in UL217 [15]. These fuels were stored in a 
temperature and humidity controlled conditioning room. The polyurethane was cut from a seat cushion of an armchair. Wood pyrolysis smoke was generated by eight beech wood blocks each $35 \mathrm{~mm}$ x $20 \mathrm{~mm}$ x $10 \mathrm{~mm}$, arranged on a $250 \mathrm{~cm}^{2}, 750 \mathrm{~kW}$ hot plate set on full power. The cotton lamp wicks smoke was generated by a staged-wick-ignition device [13] that was loaded with 32 wicks all about $210 \mathrm{~mm}$ long. Polyurethane foam was ignited to smolder by a heating wire inserted into the foam; it was turned off once the foam reached a self-sustained smoldering state. This was not always successful. If the smolder did not self sustain the test was stopped.

Two flaming fuels with different states, propylene gas and liquid heptane, were used in the FE/DE to generate "black" smoke or soot. The propylene gives a high soot yield from a diffusion flame and is ideal for use with the gas burner attached to the FE/DE, which can then output a large amount of soot at moderate fuel flow rate. Soot concentration is controlled by varying the burner fuel flow rate and by venting excess soot. Heptane soot was generated by a small pool fire located in the same section of the FE/DE where nonflaming fuels were placed. A $25 \mathrm{~cm}^{3}$ pool of heptane is poured on top of $100 \mathrm{~cm}^{3}$ of water contained in a Pyrex petri dish surrounded by a metal overflow dish. The water helps reduce the effects of the heptane boiling and splashing out of the dish. It also raises the heptane to the lip of the dish reducing lip effect on this small pool fire. Two other types of soot were generated by burning acetylene and ethylene in a separate co-flow diffusion burner used in earlier soot studies [16,17]. This burner was connected directly to the light scattering apparatus providing a repeatable alternative source of soot; it was not a part of the FE/DE.

Some common nuisance aerosols were also generated in the FE/DE and characterized. These aerosols were generated by burning (pyrolyzed) toast, over-heating (pyrolyzed) cooking oil and from a fine grain dust (ISO Fine Dust 121031;A2). The toast and cooking oil aerosols represent both a common nuisance and a hazard, as both have the potential to become fire events. Nuisance toast smoke was generated by placing two slices of white bread in a standard two-slice popup toaster, the lever of which was fixed to the power on position. The smoke concentration produced in this case had a very rapid rate of rise. The toaster was only powered for a short period compared to the sampling time, to avoid a transition to flaming. For the cooking oil, a $5 \mathrm{~cm}^{3}$ sample of corn-based cooking oil was placed in a petri dish and pyrolyzed on the hotplate, which was set at full power. The dust was introduced to the FE/DE by a screw feeder typical of dry-powder delivery systems. Loss of dust particles larger than about $10 \mu \mathrm{m}$ was caused by a honeycomb flow stabilizer before the sensor section. Gravity fractionation of the dust was also observed by differences in the transmitted light beams at the top and middle heights of the sensor section. Thus, the final sampled dust aerosol had a different size distribution compared to the original ISO fine dust.

The smoke aerosol was collected and transported into another laboratory where the light scattering apparatus was situated. The transportation method used was a $0.2 \mathrm{~m}^{3}$ drum into which about $0.12 \mathrm{~m}^{3}$ of smoke was drawn at a rate of $333 \mathrm{~cm}^{3} / \mathrm{s}(20 \mathrm{~L} / \mathrm{min})$. The drum collection method results in some settling of larger particles and wall losses in the drum. Some coagulation growth (aging) of the particles in the drum will also occur. The settling of particles mainly affect particles bigger than about $3 \mu \mathrm{m}$ and the aging of the smoke particle mainly influences the number of particles. Affects on the volume or mass of the 
smoke particles, to which light scattering is sensitive, is small in comparison to the aging affect on number concentration [11]. The size distributions of the smoke and nuisance aerosols were determined with a cascade impactor sampling directly from the FE/DE. The parameters of the distributions, the mass median aerodynamic diameter (MMAD) and geometric standard deviation (GSD), are given in Table 1.

Table 1: Table of smoke and nuisance aerosol particles characteristics: mass median aerodynamic diameter (MMAD) and geometric standard deviation (GSD); the forward angle scattering ratio and asymmetry ratio for each source is shown as well as the $q$-slope.

\begin{tabular}{lccccc}
\hline $\begin{array}{c}\text { Aerosols } \\
\text { Source or } \\
\text { Fuel }\end{array}$ & $\begin{array}{c}\text { Mass Median } \\
\text { Aerodynamic } \\
\text { Diameter } \\
(\mu \mathbf{m})\end{array}$ & $\begin{array}{c}\text { Geometric } \\
\text { Standard } \\
\text { Deviation }\end{array}$ & $\begin{array}{c}\sigma_{\mathbf{V v}}\left(\mathbf{5}^{\circ}\right) / \\
\sigma_{\mathbf{V v}}\left(\mathbf{2 0}^{\circ}\right)\end{array}$ & $\begin{array}{c}\sigma_{\mathbf{V v}}\left(\mathbf{4 5}^{\circ}\right) / \\
\sigma_{\mathbf{V v}}\left(\mathbf{1 3 5}^{\circ}\right)\end{array}$ & $\begin{array}{c}\text { Slope } \\
\text { (negative) } \\
\text { for } \\
q \geq 12 \mu \mathbf{m}^{-1}\end{array}$ \\
\hline Beech Wood & 1.5 & 1.9 & 2.0 & 15.5 & 2.7 \\
\hline $\begin{array}{l}\text { Cotton Lamp } \\
\text { Wick }\end{array}$ & 0.31 & 1.7 & 1.1 & 15.7 & 4.2 \\
\hline Polyurethane & 2.0 & 1.6 & 3.0 & 13.2 & 3.1 \\
\hline Toast & 0.43 & 1.6 & 1.3 & 17.8 & 4.1 \\
\hline Cooking Oil & 1.6 & 2.2 & 3.4 & 13.6 & 2.8 \\
\hline Dust & 2.2 & 1.8 & 7.1 & 11.3 & 2.9 \\
\hline Propylene & -- & -- & 6.3 & 4.9 & 1.8 \\
\hline Heptane & -- & -- & 6.4 & 5.6 & 2.0 \\
\hline Acetylene & -- & -- & 8.7 & 4.0 & 1.7 \\
\hline Ethylene & & & 3.8 & 4.5 & 1.7 \\
\hline
\end{tabular}

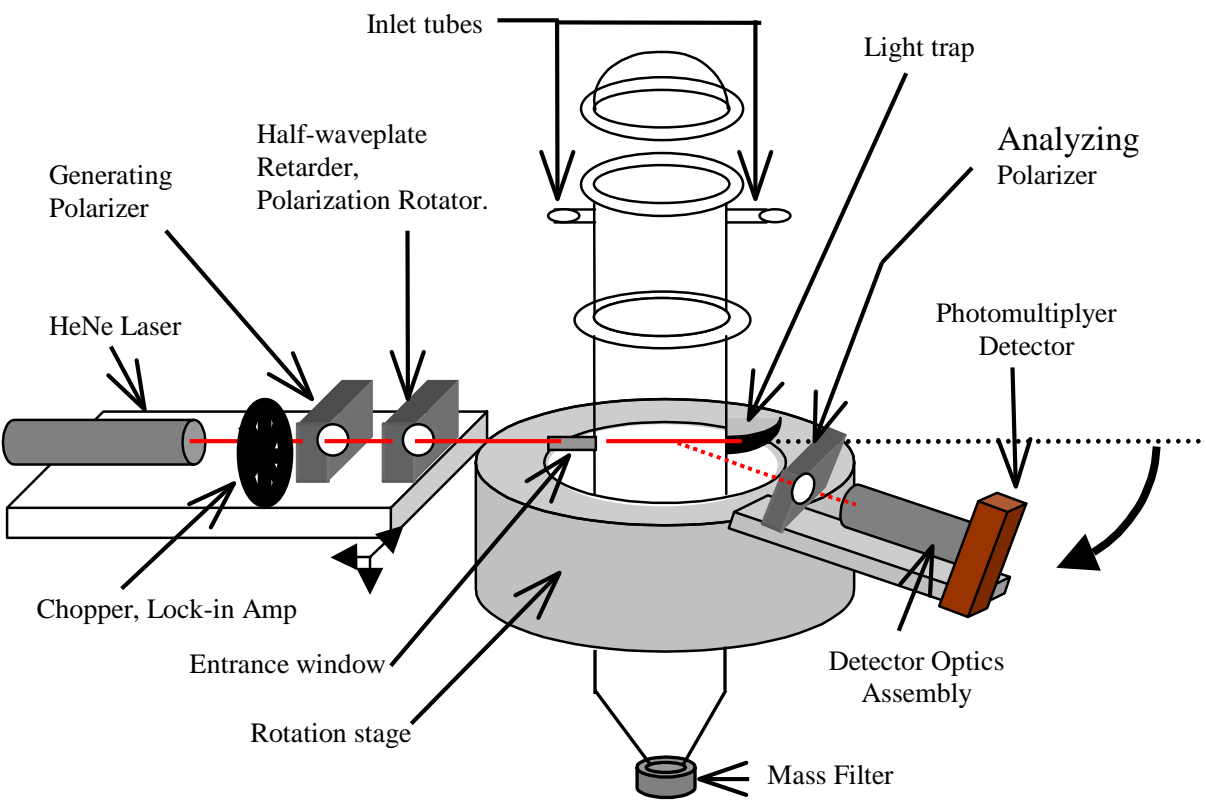

Fig. 1: The LAOF light scattering apparatus used to measure the differential mass scattering cross section. 


\section{LIGHT SCATTERING CHARACTERISTICS}

The light scattering measurements have been made with the Large Agglomerate Optical Facility (LAOF) [17] shown in Fig. 1. The LAOF determines the smoke particle's differential mass scattering cross sections for different polarizations, $\sigma_{V V}(\theta)$ and $\sigma_{H H}(\theta)$, at the He-Ne wavelength of $632.8 \mathrm{~nm}$ for scattering angles between $5^{\circ}$ to $135^{\circ}$. The first subscript denotes the incident polarization and the second denotes scattered polarization measured; $\mathrm{V}$ for vertical and $\mathrm{H}$ for horizontal to the scattering plane. The differential mass scattering cross sections measured by the LAOF have been calibrated using polystyrene (PS) spheres of nominally $500 \mathrm{~nm}$ diameter. The detector signal has been calibrated by normalizing to the absolute mass scattering cross section determined using Mie theory [18] for nominally $500 \mathrm{~nm}$ diameter monodisperse polystyrene spheres. The spheres have a density of $1050 \mathrm{~kg} / \mathrm{m}^{3}$ and a refractive index of 1.59 [19]. To determine the calibration constant, a logarithm weighted least square method is used, such that:

$\ln K=\frac{1}{N} \sum_{j}^{N} \ln \left(\frac{E_{j}}{T_{j}}\right)$,

where $K$ is the calibration constant, $E_{j}$ is the experimental result and $T_{j}$ is the theoretical result at the $j$ th scattering angle $\theta_{j}$. Mie theory gives the differential mass scattering cross section of spherical particles as the series expansion [18],

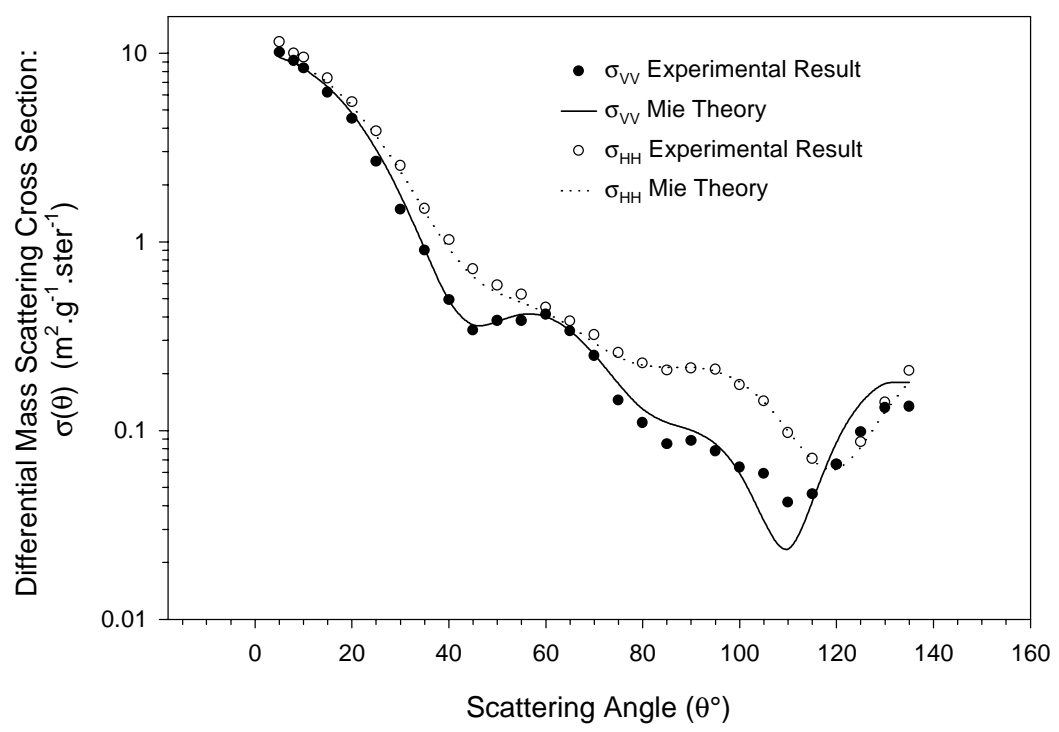

Fig. 2: The differential mass scattering cross section of nominally $800 \mathrm{~nm}$ polystyrene spheres compared to the theoretical result from Mie Theory. 


$$
\begin{aligned}
& \sigma_{V V}(\theta)=\frac{1}{\rho_{p} V_{p} k^{2}}\left|\sum_{n} \frac{2 n+1}{n(n+1)}\left(a_{n} \pi_{n}+b_{n} \tau_{n}\right)\right|^{2} \\
& \sigma_{H H}(\theta)=\frac{1}{\rho_{p} V_{p} k^{2}}\left|\sum_{n} \frac{2 n+1}{n(n+1)}\left(a_{n} \tau_{n}+b_{n} \pi_{n}\right)\right|^{2}
\end{aligned}
$$

here $a_{n}$ and $b_{n}$ are the Mie scattering coefficients that are dependent on the particle size, wavelength and refractive index of scattering particle. The angular functions are $\pi_{n}$ and $\tau_{n} ; k=2 \pi / \lambda$ is the wave number and $\lambda$ the wavelength; $\rho_{p}$ is the particle bulk density and $V_{p}$ the particles volume. The measured differential mass scattering cross section of an aerosol is determined from the volume corrected detector signal, $u(\theta)$, and aerosol mass concentration, $M$, using (polarization notation suppressed),

$$
\sigma(\theta)=\frac{u(\theta)}{M K} .
$$

The calibration was verified by generating a different size of polystyrene sphere and comparing this result to Mie theory. Nominally $800 \mathrm{~nm}$ diameter spheres were chosen for their similarity to smoke aerosol sizes. The results of one such calibration verification is shown in Fig. 2. The agreement between experiment and theory in Fig. 2 is good, while the logarithmic scale hides some variation. An uncertainty analysis (Type A, with $95 \%$ confidence level) gives a relative uncertainty of about $40 \%$ and $26 \%$, measured about the theoretical result for $\sigma_{V V}(\theta)$ and $\sigma_{H H}(\theta)$ respectively. There are two main sources of this uncertainty, the manual adjustment of polarization direction and variation in mass concentration of polystyrene particles during the 20 minute collection period.

In Fig. 3 the differential mass scattering cross sections are shown for a selection of smoke and nuisance aerosols generated in the FE/DE. The peaks and valleys obtained from monodisperse particles are "averaged out" by the relatively broad size distributions (geometric standard deviation of about 2) for the polydisperse smokes shown in Fig.3. In Table 1 the effects of size can be seen in a forward scattering ratio $\sigma_{V V}\left(5^{\circ}\right) / \sigma_{V V}\left(20^{\circ}\right)$. Small particles have weaker forward scattering than larger particles and as particle size decreases the forward scattering will become less dependent on angle.

A widely used parameter for characterizing aerosol polarization is the polarization ratio, defined as

$$
\rho(\theta)=\frac{\sigma_{H H}(\theta)}{\sigma_{V V}(\theta)} .
$$

In Fig. 4 the polarization ratio, normalized to 1 at a scattering angle of $5^{\circ}$, has been plotted for all of the aerosol sources examined. The normalization removes a spread of values that occurred at $5^{\circ}$ due to the manual setting of the polarization, which mainly affected the VV uncertainty. The results for soot from flaming fuels are very different from the non-flaming and nuisance aerosols near $\theta=90^{\circ}$. The reason for this minimum 
is related to the agglomerate morphology of the soot as discussed below. Another ratio approach which shows discrimination between soot and the other aerosols is the asymmetry ratio defined by the ratio of forward $\left(45^{\circ}\right)$ to backward angles $\left(135^{\circ}\right)$. The results for this ratio are also given in Table 1. While flaming and non-flaming smoke can be distinguished by these methods, it can be seen from Fig. 4 and Table 1 that these methods do not allow complete discrimination between non-flaming smokes and nuisance aerosols.

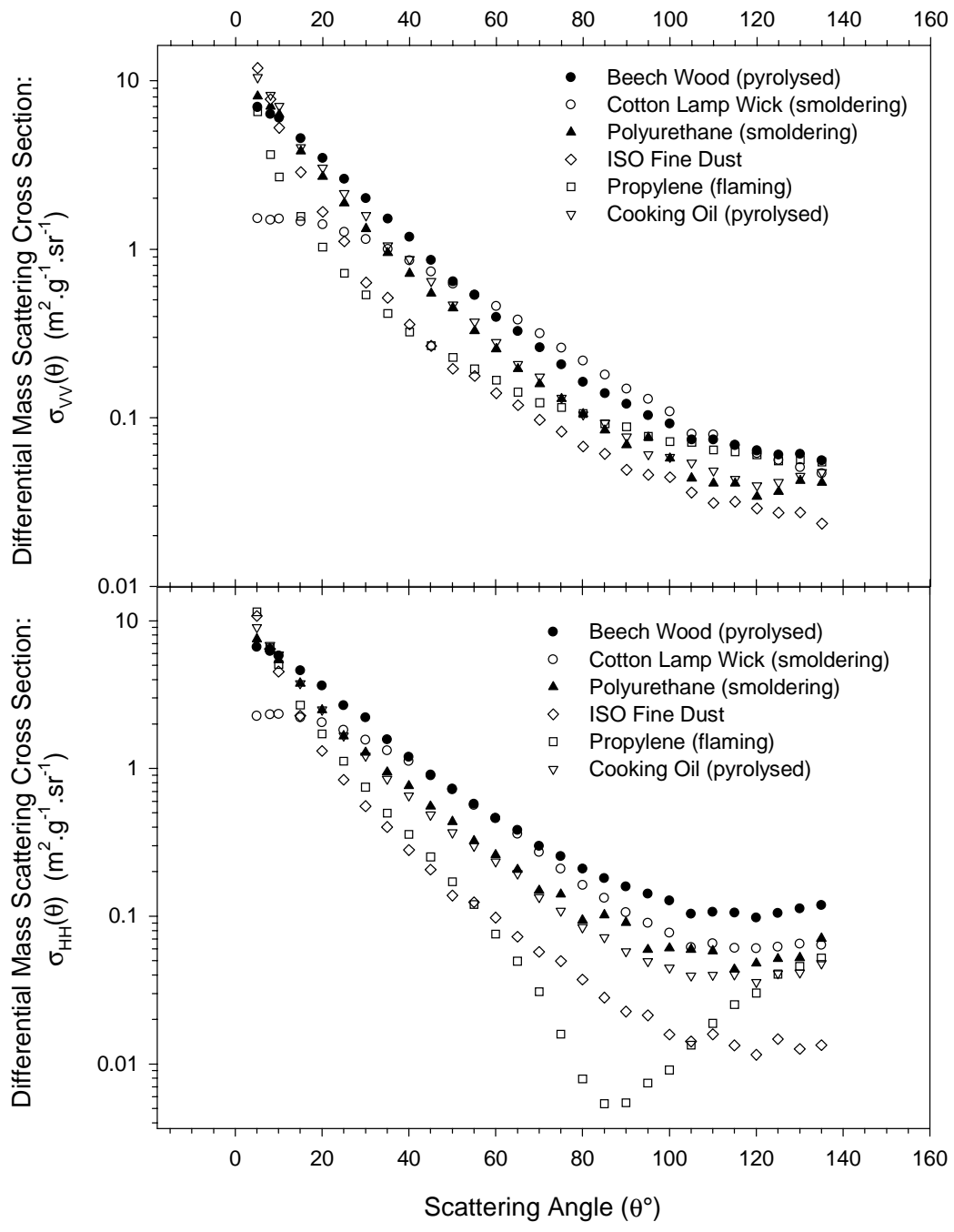

Fig. 3: Differential mass scattering cross sections of selected smoke and nuisance aerosols generated in the FE/DE. 
Another representation of scattering data is in terms of the elastic scattering wave vector magnitude or scattering parameter, $q$. Although this is a common parameter in scattering studies for soot it appears to only recently be considered with more traditional Mie scattering studies for spherical particles [8]. In Fig. 5, $\sigma_{V V}(\theta)$ is plotted as a function of $\log q$, and the slopes of all of the smoke and nuisance aerosols for $12 \mu \mathrm{m}^{-1} \leq q \leq 18.3$ $\mu \mathrm{m}^{-1}\left(75^{\circ} \leq \theta \leq 135^{\circ}\right)$ are shown in Table 1 . The slopes range from about -2 for soot to between -3 to -4 for the other aerosols. The fractal dimension of the soot agglomerates is equal to negative this slope (see Eq. 1) [16]. Differentiation between soot agglomerates and the other generated aerosols seen in Table 1 is due to the fractal nature of these agglomerates, as will be discussed below.

\section{DISCUSSION}

The differential mass scattering cross sections presented in Fig. 2 and 3 is calculated from gravimetric and angular scattering measurements. This mass based measure has an advantage in that the results can be used for assessing the response of a light scattering smoke detector, given the aerosol mass concentration (Eq. 4).

The light scattering data presented in Table 1 and Fig. 3 shows that aerosols with small particle size, such as the smoke aerosol from cotton lamp wick and burning toast, can be distinguished from larger aerosol particles examined. Discriminating smoke from

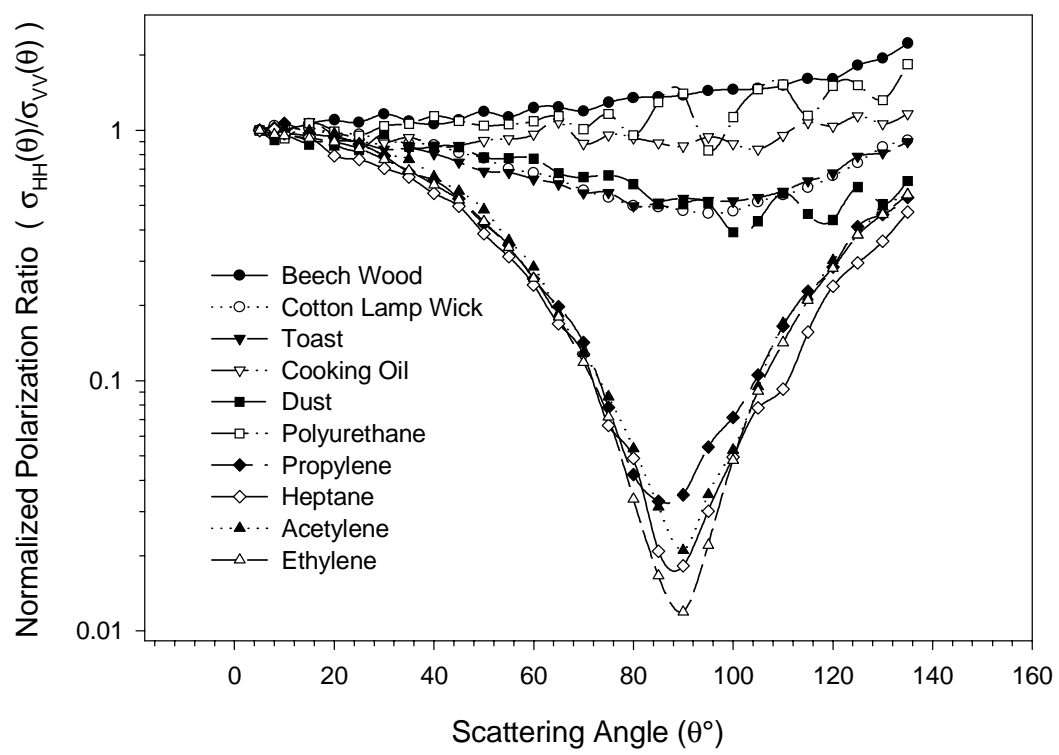

Fig. 4: The polarization ratio, $\rho(\theta)$, normalized to 1 at $\theta=5^{\circ}$ for all of the aerosol sources examined in this study. 
nuisance aerosols would be difficult using the data in Table 1 and the polarization ratio shown in Fig. 4. For example, the difficulty separating cotton lamp wick from toast smoke or cooking oil from polyurethane. The possibility exists that more data closer to scattering angles of $180^{\circ}$ would improve the ability to differentiate. However, it does not seem likely based on our data, that light scattering by itself will allow distinction between all nuisance and non-flaming fire generated aerosols.

Discrimination of soot from the other aerosols presented here is possible by various means because of the great differences in morphology. Light interacts with the electrons in matter, thus how mass is distributed in a particle affects the scattering of light. The spatial distribution of mass in a soot agglomerate is very different to that of condensed hydrocarbon droplets (spheres) generated by non-flaming fires and pyrolysis generated nuisance aerosols examined in this work. Droplet particles scatter light as described by Mie scattering theory. In the case of irregular dust particles, the scattering has similarities with Mie scattering although at backward angles Mie theory is not necessarily an acceptable approximation [20]. Soot scatters light in a fundamentally different manner to the other particles (see Eq. 1).

This leads to a novel means of discriminating between the soot agglomerates and the solid structures of other smoke and nuisance aerosols. The $q$-slopes results given in Table 1 indicate that the smoke and nuisance aerosols examined have $q$-slopes of about 3 to -4 , while slopes of about -2 to -1.7 characterize soot. More backward scattering

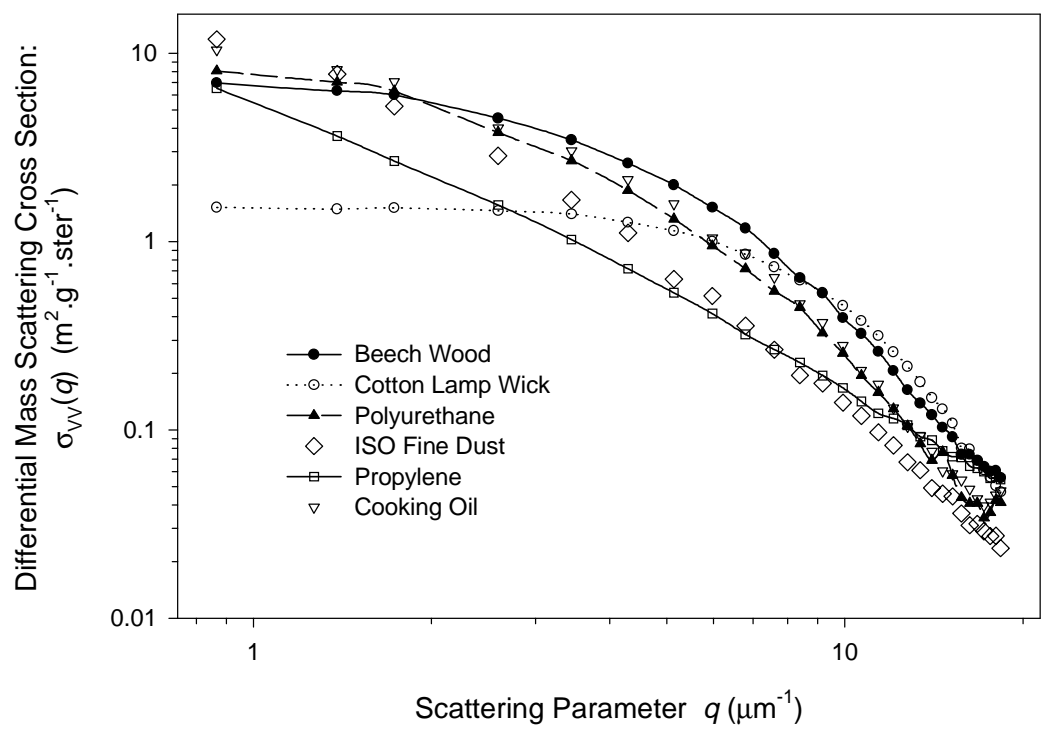

Fig. 5: Differential mass scattering cross section $\sigma_{V V}(\theta)$ as a function of the scattering wave vector, $q$. 
data, $\theta \geq 135^{\circ}$, would be of benefit in this type of discrimination. Transitions in the scattering of spherical particles occur in the range of $q$-slopes of between -2 to -4 [8]. In this study, there is an increase in the $q$-slope uncertainty at high values of $q$, due to mass loss from the drum.

The scattering mechanism of agglomerate particles can also be represented as (angular notation suppressed) [7],

$$
\sigma_{X X}=\left(S_{a g} \cdot S_{r}\right)_{X X} \text { but }\left(S_{a g}\right)_{V V} \approx\left(S_{a g}\right)_{H H}
$$

where $S_{r}$ is the Rayleigh-like scattering component and $\mathrm{X}$ denotes a given polarization. The term $S_{a g}$ arises from the interference in the far field of the scattering by the individual primary particles making up the agglomerate. The term, $S_{a g}$, can vary by a few orders of magnitude (Fig. 3) while for Rayleigh scattering, $\left(S_{r}\right)_{V V}$, is independent of angle. Since $S_{a g}$ is not strongly dependent on the polarization direction, the polarization ratio is primarily determined by the Rayleigh-like scattering from the primary spheres and results in a minimum at $\theta=90^{\circ}$ as seen in Fig. 4. Thus, soot agglomerate scattering appears to be Rayleigh-like in terms of the polarization ratio although the differential scattering for a vertical polarization direction is not at all similar to Rayleigh theory.

This fundamental difference in scattering mechanisms allows the polarization ratio to be used to discriminate between flame generated and other non-agglomerate aerosols. Practical use of soot discrimination would be for identification of a flaming fire (high hazard) vs non-flaming fire (lower hazard), possibly changing response actions. The polarization approach has previously been used to measure the degree of linear polarization for EN54 test smokes over an angular range of $5^{\circ}$ to $165^{\circ}$ [1]. Loepfe et. al. [1] found the highest degree of polarization corresponded to soot particles, a medium value existed for cotton lamp wick smoke, and that the lowest values were found for the pyrolysed wood smoke. The implication of the work by Loepfe et. al. [1] is that soot is a small Rayleigh scattering particle. The two to three orders of variation in $\sigma_{V V}(\theta)$ and Eq. 6, demonstrates that this is not the case.

Another well-used measure that differentiates soot from the other aerosols examined is the asymmetry ratio. In Table 1 the ratios of $45^{\circ}$ to $135^{\circ}$ for $\sigma(\theta)_{V V}$ are used but others are possible. The discrimination seen in this forward to backward ratio is a subsequence of the power law scattering, Eq. 1, being compared to spherical particle scattering [8].

The effect of size (reported in Table 1) on the light scattering results of Fig. 3 is mainly apparent in the forward scattering, as represented by the small angle ratio data in Table 1 . Small particles result in scattering that approaches Rayleigh scattering at forward angles, $\sigma_{V V}\left(5^{\circ}\right) / \sigma_{V V}\left(20^{\circ}\right) \sim 1$. The large particles have more pronounced forward scattering represented by the high forward angle ratio in Table 1. The particle size distribution parameters given in Table 1 indicates that smoke and nuisance aerosols in some comparisons are different (e.g. cotton from wood or dust) and in others cases similar (cotton and toast, dust and polyurethane). Discrimination based on size alone is not 
sufficient to separate the smoke and nuisance aerosols examined. Combining light scattering methods could be of benefit.

\section{CONCLUSION}

This study has presented quantitative results for the differential mass scattering cross section $\left[\mathrm{m}^{2} \cdot \mathrm{g}^{-1} \cdot \mathrm{ster}^{-1}\right]$ of various non-flaming and flaming fire generated smoke aerosols and nuisance aerosols created in the Fire Emulator/Detector Evaluator. These measurements have been determined for two linear polarizations and a scattering angle range of $5^{\circ}$ to $135^{\circ}$ at a wavelength of $632.8 \mathrm{~nm}$. The differential scattering cross section was measured in terms of aerosol mass to facilitate comparison with theory.

Analysis of scattering data by various means shows that the smoke aerosol generated by a flaming fire (soot) is distinguishable from that of a non-flaming fire or nuisance aerosol. This discrimination is possible due to the soot agglomerate structure, scattering light in a different manner to that of the other aerosols examined in this study. These discrimination methods involve calculating a ratio of forward $\left(45^{\circ}\right)$ to backward scattering $\left(135^{\circ}\right)$, determining the polarization ratio $\rho(\theta)$ near a scattering angle of $90^{\circ}$ and the scattering parameter approach using the slope of $\sigma_{V V}(q)$ vs $\log q$ for $12 \mu \mathrm{m}^{-}$

${ }^{1} \leq q \leq 18.3 \mu \mathrm{m}^{-1}\left(75^{\circ} \leq \theta \leq 135^{\circ}\right)$. The scattering parameter approach would benefit from more work with different nuisance aerosols, higher scattering angles and other wavelengths to determine the generality of the present results.

While forward scattering separates small size particles from large particles, our results indicates that this does not translate to a differentiation between non-flaming and nuisance aerosols. It does not appear that light scattering results presented in this study are adequate by themselves to make definitive separation of the non-flaming and nuisance aerosols examined. Light scattering results do distinguish soot aerosols from the other aerosols.

Acknowledgement: DWW would like to thank BFRL-NIST, for their guest researcher program in supporting this work, and Prof. Ian Thomas at CESARE.

\section{REFERENCES}

[1] Loepfe, M., Ryser, P., Tomkin, C., and Wieser, D., "Optical properties of fires and non-fire aerosols," Fire Safety Journal 29: 185-194 (1997).

[2] Meacham, B. J. and Motevalli, V., "Characterization of smoke from smoldering combustion for the evaluation of light scattering type smoke detector response," Journal of Fire Protection Engineering 4: 17-28 (1992).

[3] Aggarwal, S. and Motevalli, V., "Investigation of an approach to fuel identification for non-flaming sources using light-scattering and ionization smoke detector response," Fire Safety Journal 29: 99-112 (1997).

[4] Sorensen, C. M., "Scattering and absorption of light by particles and aggregates," Handbook of Surface and Colloid Chemistry, Birdi, K. S., CRC Press, 1997, 533558.

[5] Sorensen, C. M. and Feke, G. D., "The morphology of macroscopic soot," Aerosol Science and Technology 25: 328-337 (1996).

[6] Koylu, U. O., Faeth, G. M., Farias, T. L., and Carvalho, M. G., "Fractal and 
projected structure properties of soot agglomerates," Combustion and Flame 100: 621-633 (1995).

[7] Mountain, R. D. and Mulholland, G. W., "Light scattering from simulated smoke agglomerates," Langmuir 4: 1321-1326 (1988).

[8] Sorensen, C. M. and Fischbach, D. J., "Patterns in Mie scattering," Optics Communications 173: 145-153 (2000).

[9] Helsper, C., Fissan, H. J., Muggli, J., and Scheidweiler, A., "Particle number distributions of aerosols from test fires," Journal of Aerosol Science 11: 439-446 (1980).

[10] Bankston, C. P., Zinn, B. T., Browner, R. F., and Powell, E. A., "Aspects of the mechanisms of smoke generation by burning materials," Combustion and Flame 41: 273-292 (1981).

[11] Lee, T. G. K. and Mulholland, G., "Physical properties of smokes pertinent to smoke detector technology," National Bureau of Standards, NBSIR 77-1312, Washington, D.C., 1977.

[12] Grosshandler, W. L., "Towards the development of a universal fire emulatordetector evaluator," Fire Safety Journal 29: 113-127 (1997).

[13] Cleary, T. C., Donnelly, M., and Grosshandler, W. "The Fire Emulator/Detector Evaluator: Design, Operation and Performance," -- AUBE '01: 12th International Conference on Automatic Fire Detection, NIST, Gaithersburg, 2001, pp. 312-323.

[14] "EN54-9: Components of automatic fire detection systems, part 9: Fire sensitivity Test," Committee for Standardization (1982).

[15] "UL 217: Standard for single and multiple station smoke detectors," Underwriters Laboratories Inc., Northbrook IL (1993).

[16] Samson, R. J., Mulholland, G. W., and Gentry, J. W., "Structural analysis of soot agglomerates," Langmuir 3: 272-281 (1987).

[17] Mulholland, G. W. and Choi, M. Y. "Measurement of the mass specific extinction coefficient for acetylene and ethylene smoke using the large agglomerate optics facility," -- Twenty-Seventh Symposium (International) on Combustion, The Combustion Institute, Pittsburgh, 1998, pp. 1515-1522.

[18] Bohren, C. F. and Huffman, D. R., Absorption and scattering of light by small particles, John Wiley \& Sons, New York (1998).

[19] Mulholland, G. W., Hartman, A. W., Hembree, G. G., Marx, E., and Lettieri, T. R., "Development of a one-micrometer-diameter particle size standard reference material," Journal of Research of the National Bureau of Standards 90: 3-26 (1985).

[20] Holland, A. C. and Gagne, G., "The scattering of polarized light by polydisperse systems of irregular particles," Applied Optics 9: 1113-1121 (1970). 